\title{
PENICILLIN IN DEEP INTRA-OCULAR INFECTION
}

\section{To the Editors of THE BRITISH JOURNAL OF OPHTHALMOLOGY.}

DEAR SiRS, - As a field-ophthalmologist, I would very much like to congratulate Lt.-Col. B. W. Rycroft on his brilliant article, "Penicillin and the control of deep intra-ocular infection," in your number for February, 1945.

- May I be permitted at the same time to raise a few points in connection with the vizor and the problem of "Hospital Infection"?

The Vizor.--The introduction of the perspex anti-mine vizor marks a tremendous advance. The men will in fact really wear this type of protection whereas all previous kinds were anathema to them. Its obvious defects in the Mark I pattern will doubtless be soon overcome and the "preventable 40 per cent." be reduced.

But we must not let the success of this protective appliance make us forget the long overdue necessity for the general issue of a steel helmet of the American or German pattern. The present type in use by the British affords no protection on the side of the head and is too heavy for constant wear.

These two defects, combined with natural bravado account for the men not wearing them at all times in the forward areas.

It was calculated that of all ophthalmic casualties treated in the Mobile. Ophthalmic Unit in the Desert, some 17 per cent. had wounds of lateral entry. A large proportion of these would have been "preventable" if a coal-scuttle helmet had been available.

Hospital Infection. - It took two years of constant endeavour on the part of the M.E.F. ophthalmologists to make it more than a general surgeon's life was worth to touch an "eye" in the field. There was complete prohibition on any form of interference between the application of the first field dressing at the R.A.P. and the time of the man's arrival at the C.C.S. The rationale of this was that the environment, overwork, etc., at a busy Field Surgical Unit or Dressing Station during battle-periods raised enormously the potentiality for hospital infection. Lash-cutting, unsterile atropine, irrigation by the O.R.A., repeated change of dressings causing the patients to squeeze out the remainder of the partly prolapsed ocular contents : all these are relevant points.

At the C.C.S. was located the M.O. Unit. There the toilet of the wound could take place unhurried and not as an afterthought to general surgery:-

His oral sulphonamide had been continued throughout the time of evacuation, and now was further reinforced by local albucid, atropine and in the later days penicillin-sulpha-powder. Thereafter firmly bandaged, with another "Verboten" written all over his card, he was passed back to the base hospital ophthalmologist.

Returns obtained did not show a high incidence of infected wounds for the M.E.F. As the ophthalmologist most concerned 
with the Sicilian casualties, I have a point to make with regard to "C.M.F. casualties are cleaner than the Sicilian or Tunisian cases." To date I have received only five "follc v-up" reports on the cases that I treated and evacuated; in fact I am in the middle of a further attempt to get more information about them. Also, whilst in the C.M.F. I was informed that it was not possible to get a comprehensive survey.

So the above comparison must be regarded as based solely on án impression formed, not on statistics.

To conc de may I emphasize once more with Colonel Rycroft the absolute necessity for the instillation of penicillin in every wound of the eye, backed with the full exhibition of sulphonamides, systemically. . At the same time I would submit that a policy of permitting the overworked "general" surgeon to attempt ophthalmic wound toilet is controversial.

\section{I am, Sir, Your obedient servant,}

\section{G. C. DANSEY-BRownING,} Major, R.A.M.C.

OPHTHALMIC CENTRE,

FENHAM BARRACKS, NEWCASTLE-ON-TYNE.

April 12, 1945.

\section{INDUSTRIAL OPHTHALMOLOGY}

1

To the Editors of. THE BRITISH Journal OF OPHTHalmology.

DEAR SiRs,-The Institute of Ophthalmology proposes to devote a considerable proportion of its funds to Industrial Ophthalmology. In view of the absence of any co-ordinated work in this field it is felt that a national survey of workers, and of work already accomplished, is a necéssary preliminary to the undertaking of research on any specific aspect of this very extensive subject.

The Institute therefore asks all who have routine experience in any branch of Industrial Ophthalmology, or who have undertaken original work bearing upon it, to communicate with the Institute stating briefly their experience and defining the aspect of the work with which they are most familiar-medical supervision, safety, lighting, industrial psychology, etc. It is the Institute's policy to promote the investigation of Industrial Ophthalmic_problems in the districts in which they arise. It is hoped that those replying to this request will be willing to co-operate in their own areas and in their special fields of interest and experience as the National scheme develops.

This invitation is extended not only to individual workers but also to research and other organisations concerned. The funds will be distributed on the recommendati.... f the Scientific Executive 